\title{
Analysis on Well-being Difference in Terms of Job Type between Chinese Urban Residents and Mobile Residents
}

\author{
Xin-Yi ZHANG \\ International Business School, Beijing Language and Culture University, Beijing, China \\ zhangxinyi@blcu.edu.cn
}

Keywords: Well-being difference, Appleton decomposition method, Job skill training.

\begin{abstract}
In the urban-rural dual structure, there is an obvious difference in terms of job between Chinese urban residents and mobile residents, thus causing well-being difference between the two. This paper makes a decomposition of well-being difference through using Appleton decomposition method. The result shows that the well-being difference between Chinese urban residents and mobile residents is mainly caused by well-being difference in the same job type, while the well-being difference brought by different job types is not large; job entry restriction and discrimination is the main reason for causing the well-being difference between Chinese urban residents and mobile residents, while personal characteristics and human capital elements play a limited role. On this basis, this paper puts forward the relevant policy recommendations.
\end{abstract}

\section{Introduction}

Since China implemented the reform and opening-up policy, China's floating population has expanded unceasingly. On one hand, population flow normalization has provided laborers with the opportunity of fair competition, and has improved their living standards; on the other hand, over-high population flow cost multiplies the surviving burden of floating population. The resulting well-being difference between mobile residents and urban residents aroused high attention of scholars (John Knight, 2010; Tian Guoqiang, 2006). The census data in 2012 show that the population with separation of registered and actual residences was 279 million people in China, an increase of 7.89 million people from the end of the previous year, in which the floating population was 236 million people. With acceleration of China's urbanization process and surplus rural labor force with huge potential, the future floating population will continue to increase (Sun Sanbai, et al, 2012) [8]. It is worth noting that, in addition to accelerated urbanization process, factors such as family, enterprise and others also affect laborers' migration decisions, China's huge regional differences also prompt a large number of urban population to flow between cities. Because of this, the well-being difference between floating residents and urban residents is considered as the focus of concern. Relevant literatures generally view that mobile residents often cannot enjoy equal treatment in terms of employment, wage and welfare as urban residents do thus resulting in the significant well-being difference between the two. (Chen Zhao, 2009; Huang Shaoan, 2009; Zhang yuan, 2011; Maeer, 2009; Nord, 1998; Peters, 1992).

In China's urban-rural dual structure, there is a natural difference in different job types between mobile residents and urban residents. The research made by Feng Ying (2006) shows that the discrimination against floating population's entry into some industries has long existed in the Chinese society. There are many causes of difference in job type between the two, Pang Wen (2004) et al views that there are three main reasons for why mobile residents can not enter some sectors: first, employment discrimination. Due to census register, identity and other non-economic factors, the floating population can not enjoy equal employment opportunity as urban residents do; without urban registered permanent residence, the floating population are artificially restricted at low-level labor market, meanwhile, the existence of crowding effect makes the floating population face the fate of being dismissed at any time; second, job discrimination, which means the floating population can not freely choose jobs according to market rule, and are subject to artificial job segregation; in real life, job discrimination is manifested as city government's control on total number of floating population, restriction on occupation and work type, and control on city first and countryside 
second, etc.; third, promotion discrimination, which means the floating population are excluded and cannot enjoy equal opportunities for title promotion and position promotion as city workers do.

Under the condition of the current system, what impact does the job type factor the floating residents choose after migration exert on their well-being sense? Compared with urban residents, what characteristics exist in the well-being difference between the two caused by job type factor? These are issues that are in urgent need of argument. In terms of the well-being difference between the two, such factors as job type difference between mobile residents and urban residents, and the job discrimination suffered by the two, are directly manifested as significant difference in well-being index between urban residents and mobile residents. To this end, we have demonstrated, from a new angle, the importance of job type factor, especially factors within the same job type, to the improvement of well-being of the two, and we have also drew a conclusion that, while increasing residents' incomes, we must give full consideration to the impact on mobile residents by gradual elimination of household registration, identity and other institutional discrimination.

\section{Introduction and Construction of Decomposition Model of Well-being Difference in Terms of Job Type}

According to CHIP2007 survey data, this paper divides the residents' jobs into four categories: fixed worker in enterprises and institutions, long-term contract worker, short-term contract worker, temporary or non-contract worker, as well as private owner, self-employed laborer or others. From the job distribution of urban residents and floating residents (Table 1), it can be seen that the probability for urban residents' becoming fixed workers in enterprises and institutions is obviously higher than that for floating residents, while mobile residents have higher probability of being engaged in private or individual business, which shows that there is a great inconsistency in terms of job choice between urban residents and mobile residents. Is it caused by their personal characteristics or the identity of urban residents and mobile residents? This question will be further analyzed in the demonstration part of this paper. Meanwhile, this paper finds that the well-being sense of urban residents, no matter what jobs they are taking up, is not lower than that of mobile residents, this case is particularly obvious in terms of job distribution of fixed workers and long-term contract workers, in fact, through calculation, the average value of well-being of urban residents is 3.49 , and that of floating residents is 3.37 , with a difference of 0.12 . Therefore, it is considered that well-being is related to whether the person is an urban resident or floating resident, as well as his or her job type.

Table 1 Job Type and Well-being Sense of Urban Residents or Mobile Residents

\begin{tabular}{|l|l|l|l|l|l|l|}
\hline & \multicolumn{3}{|c|}{ Urban Residents } & \multicolumn{3}{c|}{ Mobile Residents } \\
\hline & Frequency & $\begin{array}{c}\text { Well-being } \\
\text { Mean } \\
\text { Value }\end{array}$ & $\begin{array}{c}\text { Standard } \\
\text { Deviation }\end{array}$ & Frequency & $\begin{array}{c}\text { Well-being } \\
\text { Mean } \\
\text { Value }\end{array}$ & $\begin{array}{c}\text { Standard } \\
\text { Deviation }\end{array}$ \\
\hline $\begin{array}{l}\text { Fixed workers in } \\
\text { enterprises and } \\
\text { institutions }\end{array}$ & 2728 & 3.52 & 0.83 & 10 & 3.2 & 0.63 \\
\hline $\begin{array}{l}\text { Long-term contract } \\
\text { worker }\end{array}$ & 964 & 3.49 & 0.89 & 93 & 3.23 & 0.87 \\
\hline $\begin{array}{l}\text { Short-term, } \\
\text { temporary or } \\
\text { non-contract workers }\end{array}$ & 667 & 3.4 & 0.9 & 503 & 3.4 & 0.85 \\
\hline $\begin{array}{l}\text { Private owner, } \\
\text { self-employed } \\
\text { laborer or others }\end{array}$ & 397 & 3.47 & 0.89 & 1294 & 3.37 & 0.79 \\
\hline
\end{tabular}


Secondly, with the help of a Blinder - Oaxaca model, Knight (2010) has systematically studied the well-being gap between Chinese mobile residents and urban residents. He decomposed the well-being gap between mobile residents and urban residents into two parts, i.e. characteristics correlation and coefficient correlation, the decomposition process is as follows:

$$
\begin{aligned}
& \bar{S}_{u}-\bar{S}_{m}=\bar{X}_{u} \beta_{u}-\bar{X}_{m} \beta_{m} \\
& =\left(\bar{X}_{u}-\bar{X}_{m}\right) \beta_{u}+\bar{X}_{m}\left(\beta_{u}-\beta_{m}\right) \\
& \bar{S}_{u}-\bar{S}_{m}=\bar{S}_{u} \beta_{u}-\bar{S}_{u} \beta_{m} \\
& =\left(\bar{S}_{u}-\bar{S}_{m}\right) \beta_{m}+\bar{S}_{u}\left(\boldsymbol{\beta}_{u}-\beta_{m}\right)
\end{aligned}
$$

In which, $S$ stands for well-being, $X$ represents the personal characteristic of the respondent, $\beta$ represents the structure of well-being function (coefficient matrix), $\mathrm{u}$ represents urban residents, $\mathrm{m}$ represents mobile residents. The decomposition processes in Equation (1) and Equation (2) are obtained respectively by using well-being function of urban residents and mobile residents. Although Knight's research results are groundbreaking, the model has the problem of "index benchmark", and weakens the direct impact of job choice on well-being. Based on this, in order to overcome the negative influence brought by the index benchmark problem, this paper adds the job type variable, in order to optimize the constitution of well-being gap between urban residents and mobile residents, and explore the impact of job type on well-being gap between urban residents and mobile residents. By referring to Appleton (1999)'s method of decomposition of wage and gender difference, the well-being gap between urban residents and mobile residents is decomposed.

First of all, regression is made on the well-being of urban residents and mobile residents with different job type ( $\mathrm{j}$ represents job type) :

$$
\begin{aligned}
& S_{j}^{u}=X_{j}^{u} \beta_{j}^{u}+\mu_{j}^{u} \\
& S_{j}^{m}=X_{j}^{m} \beta_{j}^{m}+\mu_{j}^{m}
\end{aligned}
$$

Seek mean value of the two equations:

$$
\begin{aligned}
& \bar{S}_{j}^{u}=\overline{\boldsymbol{X}}_{j}^{u} \boldsymbol{\beta}_{j}^{u} \\
& \overline{\boldsymbol{S}}_{j}^{m}=\overline{\boldsymbol{X}}_{j}^{m} \boldsymbol{\beta}_{j}^{m}
\end{aligned}
$$

Equation (5) and Equation (6) respectively add up all weights with the probability of all job types, and obtain the well-being of urban residents and mobile residents:

$$
\begin{aligned}
& \bar{S}^{u}=\sum_{j} P_{j}^{u} \bar{S}_{j}^{u}=\sum_{j} P_{j}^{u} \bar{X}_{j}^{u} \boldsymbol{\beta}_{j}^{u} \\
& \bar{S}^{m}=\sum_{j} P_{j}^{m} \bar{S}_{j}^{m}=\sum_{j} P_{j}^{m} \bar{X}_{j}^{m} \boldsymbol{\beta}_{j}^{m}
\end{aligned}
$$

Further, the well-being gap between urban residents and mobile residents, i.e. Equation (7) Equation (8): 


$$
\begin{aligned}
& \bar{S}_{u}-\bar{S}_{m} \\
& =\sum_{j}\left(\bar{p}_{j}^{*}\left(\bar{X}_{j}^{u}-\bar{X}_{j}^{m}\right) \beta_{j}\right. \\
& +\sum_{j} \bar{p}_{j}^{*} \bar{X}_{j}^{u}\left(\beta_{j}^{u}-\beta_{j}\right)+\sum_{j} \bar{p}_{j}^{*} \bar{X}_{j}^{m}\left(\beta_{j}-\beta_{j}^{m}\right) \\
& +\sum_{j} \bar{S}_{j}^{u}\left(\bar{p}_{j}^{u *}-\bar{p}_{j}^{*}\right)+\sum_{j} \bar{S}_{j}^{m}\left(\bar{p}_{j}^{*}-\bar{p}_{j}^{m *}\right) \\
& +\sum_{j} \bar{S}_{j}^{u}\left(\bar{p}_{j}^{u}-\bar{p}_{j}^{u *}\right)+\sum_{j} S_{j}^{m}\left(\bar{p}_{j}^{m *}-\bar{p}_{j}^{m}\right)
\end{aligned}
$$

In which, $\beta_{j}$ is a weighted average of the regression coefficient of urban residents and the regression coefficient of mobile residents, this weighted average is taken as the benchmark:

$$
\begin{aligned}
& \Omega=\left(X^{\prime} X\right)^{-1}\left(X_{u} \cdot X_{u}\right) \\
& \beta_{j}=\Omega \beta_{j}^{u}+(1-\Omega) \beta_{j}^{m}
\end{aligned}
$$

$\vec{p}_{j}$ stands for the average employment probability of an individual (i) in job (j) without discrimination.

Assuming the employment probability of the individual (i) in job (j) is decided by multinomial logit mechanism, i.e. if the individual (i) has the characteristics $\mathrm{q}_{\mathrm{i}}$, the employment probability of the individual (i) in job (j) is:

Urban residents:

$$
\left.p_{j}^{i}=\exp q_{j}^{u} q_{i}\right) \sum_{j} \exp q_{i}
$$

Mobile residents:

$$
p_{j}^{i}=\exp \left(\gamma_{j}^{m} q_{i}\right) / \sum_{j} \exp \left(\gamma_{j}^{m} q_{i}\right)
$$

$$
p_{j}^{i *}=\exp \left(\gamma_{j} q_{i}\right) / \sum_{j} \exp \left(\gamma_{j} q_{i}\right)
$$

$$
p_{j}^{u^{*}} \text { is averaged into } \bar{p}_{j}^{u^{*}}, p_{j}^{m^{*}} \text { is averaged into } \bar{p}_{j}^{m^{*}} \text {, and } p_{j}^{*} \text { is averaged into } \bar{p}_{j}^{-*} \text {. }
$$

The first three items in Equation (9) represent the well-being index difference within the same job between urban residents and mobile residents, the later four items in Equation (9) represent the well-being index difference in different jobs between urban residents and mobile residents. These items are respectively personal endowment difference, preference given to urban residents (within the same job), punishment on mobile residents (within the same job), comparative advantage factor owned by urban residents, disadvantage factors owned by mobile residents, preference to city residents (between jobs), and punishment on mobile residents (between jobs). In general, the sum of the first item, the fourth item and the fifth item represents the well-being difference caused by resident endowment characteristics; the sum of the second, third, sixth and seventh items represents the impact of employment discrimination and job discrimination on the well-being of mobile residents. In which, the sum of the second and third items represents the impact of well-being discrimination, and the sum of the sixth and seventh items represents the impact of job type discrimination. 


\section{Decomposition of Well-being Difference between China's Urban Residents and Mobile Residents}

This paper calculates the mean value of all independent variables of all job types of urban residents and migrant laborers, and uses the mean value to decompose the well-being index difference between the two, with specific results are shown in Table 2.

Table 2 Decomposition of Well-being Difference between Urban Residents and Mobile Residents

\begin{tabular}{|c|c|c|c|}
\hline & Well-being Index & Percentage & Percentage \\
\hline Combined Index Difference & 0.3897 & 100.00 & \\
\hline Difference within the same job & 0.2482 & 63.69 & 100.00 \\
\hline $\begin{array}{l}\begin{array}{c}\text { Explainable Part (personal endowment } \\
\text { difference) }\end{array} \\
\text { (if }\end{array}$ & 0.0405 & 10.39 & 16.32 \\
\hline Unexplainable Part & 0.2077 & 53.30 & 83.68 \\
\hline Preference given to urban residents & 0.1163 & 29.84 & 46.86 \\
\hline Punishment on mobile residents & 0.0914 & 23.45 & 36.83 \\
\hline Difference between jobs & 0.1415 & 36.31 & 100.00 \\
\hline Explainable Part & 0.0490 & 12.57 & 34.63 \\
\hline $\begin{array}{l}\text { Comparative advantage factor owned by } \\
\text { urban residents }\end{array}$ & 0.0130 & 3.34 & 9.19 \\
\hline $\begin{array}{l}\text { Disadvantage factors owned by mobile } \\
\text { residents }\end{array}$ & 0.0360 & 9.24 & 25.44 \\
\hline Unexplainable Part & 0.0925 & 23.74 & 65.37 \\
\hline Preference given to urban residents & 0.0296 & 7.60 & 20.92 \\
\hline Punishment on mobile residents & 0.0629 & 16.14 & \\
\hline Total of the explainable parts & 0.0895 & 22.97 & \\
\hline Total of the unexplainable parts & 0.3002 & 77.03 & \\
\hline
\end{tabular}

On the basis of Appleton method, well-being difference between urban residents and mobile residents comes from two aspects: within one position and between positions. First of all, difference within the same position is composed of explainable part and unexplainable part (preference given to urban residents, punishment on mobile residents); similarly, difference between jobs can be decomposed into explainable part (superior skill factor owned by urban residents, poor skill factor owned by mobile residents) and unexplainable part (preference given to urban residents, punishment on mobile residents). Data analysis shows that the overall value of well-being difference between urban residents and mobile residents is 0.3897 . In which, the difference within the same position is 0.2482 , accounting for $63.69 \%$; the difference between positions is 0.1415 , accounting for $36.31 \%$. This shows that the well-being difference within the same position has greater impact on well-being index difference than well-being difference between positions. As far as well-being difference within the same position is concerned, personal endowment difference is 0.0405 , accounting for $10.39 \%$ of the overall difference; the difference arising from preference given to urban residents and punishment on mobile residents due to institutional or policy barriers (discrimination) are $0.1163(29.84 \%)$ and $0.0914(23.45 \%)$ respectively. As far as well-being difference between positions is concerned, the difference arising from comparative advantage possessed by urban residents is $0.013(3.34 \%)$, while the difference arising from disadvantage possessed by mobile residents is $0.036(9.24 \%)$, nearly three times that of the former; in terms of the unexplainable part, the difference in terms of preference given to urban residents and punishment on mobile residents are $0.0296(7.60 \%)$ and $0.0629(16.14 \%)$ respectively. Overall, in the constitution of overall well-being index difference, $22.97 \%$ can be explained by using resident endowment difference, while the percentage of the unexplainable part is as high as $77.03 \%$. It is worth mentioning that the difference between institutional barriers and policy factors accounts for the main part of the unexplainable part. 


\section{Conclusions and Policy Implications}

The above analysis shows that, the current well-being difference between Chinese urban residents and mobile residents mainly comes from policy barriers and discrimination within the same position. For a long time, mobile residents have been mostly at a disadvantage in terms of employment choice, which greatly dampens their well-being and causes the well-being difference within the same position between the two to reach $83.68 \%$ (accounting for $53.30 \%$ of total difference); the well-being difference between positions accounts for $36.31 \%$ of overall well-being difference between residents, discrimination and other unexplainable factors account for as high as $65.37 \%$ of the well-being difference between positions; There are two reasons that lead to discrimination against mobile residents within the same position. First, discrimination in pure sense, that is, employers pay lower salaries to mobile residents under the same conditions; second, mobile residents lack necessary social resources, with less opportunity for position promotion; they are in a marginalized position in the current urban-rural dual system, which disables them to enjoy same opportunity for title promotion and position promotion as urban laborers do. The difference in terms of position choice between urban resident population and floating population will certainly exert a huge impact on social security, income, mental health, life development and other aspects, and ultimately affect the well-being difference between the two groups (Jiang Jie, Ji Tao, 2003). Therefore, firstly, the governments at all levels should actively cultivate labor market, eliminate institutional discrimination and barriers within the industry, gradually weaken the impact of household registration system on resident discrimination within the industry; Secondly, relevant departments should strengthen policy-related subsidies offered to mobile residents within the industry, through training, social publicity and other means, improve work skills of mobile residents, create a good social atmosphere of employment equality and fair competition within the industry, and promote the building of a harmonious society; Thirdly, the governments should accelerate the construction of new urbanization, cultivate regional labor market, reduce workers' employment cost, realize local employment of mobile residents, gradually change the current situation that the floating population excessively concentrate in big cities, and make them become the main force of new countryside construction.

\section{References}

[1] John Knight, Great Expectations? The Subjective Well-being of Rural-Urban Migrants in China, World Development, Vol. 38, No. 1 (2010).

[2] Li Xiaoying, Zhao Zhong, Evolution of Employment Relations in Urban China, Economic Research Journal , 9(2012).

[3] Lu Yuanping, Zhang Kezhong, Economic Growth, Pro-poor Spending and National Happiness-Empirical Study Based on China's Well -being Data, Economist, 11(2010).

[4] Luo Chuliang, Urban-Rural Divide, Employment, and Subjective Well-Being, China Economic Quarterly, 3(2006).

[5] Qi Liangshu, Income, Income Inequality and Health: The Impacts of Rural-urban Gap and Occupational Status, Economic Research Journal,11( 2006).

[6] Wang Peng, Analysis of Income Difference on China Residents Subjective Well-being, Chinese Journal of Population Science, 3(2011).

[7] Zhu Jianfang , Yang Xiaolan, An Empirical Study on the Relation between Happiness and Income during Transitional Times, Statistical Research, 4(2009).

[8] Information on http://www.stats.gov.cn/tjfx/jdfx/t20130118_402867146.htm. 